\title{
Desastres e vulnerabilidade na Região Serrana do Rio de Janeiro (RSRJ)
}

\author{
César Marques ${ }^{1}$ \\ Daniel Cesario Baesso ${ }^{2}$
}

\begin{abstract}
Resumo: As chuvas ocorridas em janeiro de 2011 na Região Serrana do Rio de Janeiro deflagraram o processo de um desastre com elevado impacto social, econômico e institucional. Neste artigo, a partir do diálogo entre vulnerabilidade, desastres e justiça ambiental, reiteramos que a interpretação de tal ocorrência não estaria nas suas características "naturais", seja pela pluviometria ou no seu relevo, mas sim no encontro dessas com padrões de desenvolvimento, de uma forma ampla, e as condições de vulnerabilidades existentes. Reitera-se a perspectiva de que a vulnerabilidade ao risco de desastre é produto da complexa relação sociedade e natureza, sendo um conceito crucial para a compreensão do desastre e da justiça ambiental, sendo que as contribuições de Daniel Hogan foram centrais para o desenvolvimento dessa área, especialmente no caso brasileiro. Como resultados, indicamos que o desastre ocorreu em uma região com existência de populações vivendo em áreas de risco de forma ampla, tendo desencadeado processos que se desdobraram tanto institucionalmente como após os eventos de 2011.
\end{abstract}

Palavras-chave: Desastres. Risco. Vulnerabilidade.

\section{Disasters and vulnerability in the Mountainous Region of Rio de Janeiro State}

\begin{abstract}
The rains of January 2011 in the mountainous region of Rio de Janeiro State triggered a process of a high-impact disaster within multiple dimensions, such as social, economic and institutional. The interpretation of such occurrence would not

\footnotetext{
${ }^{1}$ Mestre e doutor em Demografia pela UNICAMP. Professor da Escola Nacional de Ciências Estatísticas (ENCE/IBGE). Rio de Janeiro, RJ. E-mail: cesarmcs@gmail.com.

2 Mestre em Planejamento Urbano e Regional/Demografia pela Escola Nacional de Ciências Estatísticas (ENCE/IBGE). Rio de Janeiro, RJ. E-mail: danielbaesso@gmail.com.
}

Submetido em: 06/04/2021 - Aceito em: 04/10/2021. 
Desastres e vulnerabilidade..

rely in their "natural" characteristics, such as its high rainfall or the mountainous relief, but in the encounter of these with development patterns and the specific conditions of existing vulnerabilities. In this article we dialogue with the concepts of vulnerability, disasters and environmental justice to assess the populations at risk in the affected municipalities and to reflect on some of the processes triggered by the disaster. Considering Daniel Hogan's contributions in the field of vulnerability, the article considers that the vulnerability to disaster risk is the product of the complex relationship between society and nature, being a crucial concept for the comprehension of disaster and environmental justice.

Keywords: Disasters. Risk. Vulnerability.

\title{
Desastres y vulnerabilidad en la Región Montañosa de Río de Janeiro
}

\begin{abstract}
Resumen: Las lluvias en la región montañosa de Río de Janeiro en enero de 2011 desencadenaron el proceso de un desastre con alto impacto social, económico e institucional. La interpretación de tal ocurrencia no estaría en las características "naturales" de la región, como sus elevadas precipitaciones o relieve montañoso, sino en el encuentro de estas con los patrones de desarrollo y las condiciones específicas de las vulnerabilidad existentes. En este trabajo, a partir del diálogo entre vulnerabilidad, desastres y justicia ambiental, se analiza el perfil de la población en riesgo en los municipios afectados y algunos de los procesos desencadenados por tal desastre. Considerando los aportes de Daniel Hogan en el campo de la vulnerabilidad, el artículo parte de la perspectiva de que la vulnerabilidad al riesgo de desastres es producto de la compleja relación entre sociedad y naturaleza, siendo un concepto crucial para la comprensión del desastre y de la justicia ambiental.
\end{abstract}

Palabras clave: Desastres. Riesgos. Vulnerabilidad.

\section{Introdução}

Particularmente na relação população e ambiente, Daniel Joseph Hogan obteve destaque como um dos pesquisadores mais influentes na consolidação do debate sobre a questão ambiental ao longo da segunda metade do século XX. Nesse, o pesquisador denotou como a partir da década de 1950 houve a disseminação de desastres e sua relativa documentação, a decorrente insegurança associada ao desenvolvimento econômico e tecnológico e a demanda em compreender tanto como processos populacionais alteram o ambiente, como os fatores ambientais influenciam a 
dinâmica demográfica (HOGAN, 2007a). Consolidou assim uma agenda de pesquisa em múltiplas áreas, com a inserção das ciências humanas e dos estudos populacionais na compreensão sobre a mudança ambiental (HOGAN, 2001; 2007b) e da vulnerabilidade (MARANDOLA JR. e HOGAN, 2007; HOGAN e MARANDOLA JR., 2008).

Nessa agenda, uma das questões fundamentais foi a realização de estudos de caso apoiados na interdisciplinaridade e no trabalho conceitual, como demonstram as pesquisas sobre mobilidade e poluição em Cubatão (HOGAN, 1993) e os projetos "Dinâmica intra-metropolitana e vulnerabilidade sóciodemográfica nas metrópoles do interior paulista: Campinas e Santos" e "Urban growth, vulnerability and adaptation: social and ecological dimensions of climate change on the Coast of São Paulo", conduzidos já nos anos finais de sua vida.

Considerando os legados e avanços de tal agenda, esse artigo tem como objetivo contribuir à compreensão do que se convencionou como desastre na Região Serrana do Rio de Janeiro (RSRJ) em 2011. Para isso, se colocam os debates sobre desastres, vulnerabilidade e sua interface com a justiça ambiental, são analisadas as dinâmicas relacionadas ao desastre de 2011 e o perfil sociodemográfico das populações que habitam em áreas de risco. $\mathrm{O}$ artigo dialoga com a obra de Daniel Hogan considerando que tanto seu campo de atuação como a rede de pesquisadores formados direta e indiretamente (reconhecível nas citações elencadas) foram legados fundamentais para o contínuo avanço da compreensão de questões ambientais que considerem a perspectiva social e demográfica.

Metodologicamente, a pesquisa considera os elementos conceituais do diálogo entre desastres, vulnerabilidade e justiça ambiental e utiliza os dados da Base Territorial Estatística de Áreas de Risco (BATER), criada pelo Centro Nacional de Monitoramento e Alertas de Desastres Naturais (Cemaden) e Instituto Brasileiro de Geografia e Estatísticas (IBGE) para a análise das populações em áreas de risco. Adicionalmente, foram realizados trabalhos de campo entre novembro e dezembro de 2019 em Nova Friburgo 
$|4|$

Desastres e vulnerabilidade...

e Teresópolis, com visitas às áreas atingidas e aplicação de questionários semiestruturados a atores chave que experenciaram o desastre de 2011.

\section{Desastres, vulnerabilidade e justiça ambiental}

Se etimologicamente o desastre é uma adversidade danosa influenciada pelos astros, é na disputa conceitual e simbólica da modernidade que sua qualificação como "natural" ganha evidência e o consenso dificilmente é alcançado (MARCHEZINI e FORINI, 2019). Coexistem argumentações de que os desastres surgem quando fenômenos naturais causam danos em áreas habitadas pelo ser humano (SILVA e POLETO, 2015) com aquelas em que o evento natural não é sinônimo de perigo natural, sendo os desastres resultantes de fenômenos naturais cujos danos excedem as capacidades de resposta (SAITO, 2016). Concorreriam como atritos a concordância ao menos três pontos: o maior espaço das correntes que entendem o desastre como um acontecimento físico em relação aos que o consideram como uma construção social; a implicação de juízo de valores e de subjetividades e a crescente complexidade de eventos sociais, políticos e físicos a ele relacionados (VALÊNCIO, 2010).

Nas ciências sociais, é consolidada a problematização de que o "natural" é responsável pelo desastre, em detrimento da análise da sua dinâmica mais ampla. Como já colocado na origem de tal discussão, diversos autores ressaltam que os desastres ocorrem no encontro de eventos físicos de perigo com condições de vulnerabilidade social que levam a alteração da "normalidade", demandando respostas de emergência que permitam a criação de condições básicas de reprodução da vida (ROMERO e MASKREY, 1993; CARDONA et al., 2012). Essa perspectiva é oposta a visão tecnicista do desastre, sendo pautada por uma compreensão mais profunda do mesmo, incluindo ações governamentais, intenções políticas, a dinâmica populacional, o histórico de ocupação territorial e a exclusão social presente na dinâmica dos desastres (KELMAN, 2020; VALENCIO, et al., 2006; VALENCIO, 2010; 
CARMO E ANAZAWA, 2014; RODRIGUES, 2015; MARQUES, 2015).

Sem desconsiderar que a visão técnica traria elementos, modelos e metodologias no auxílio às políticas de prevenção, preparação da comunidade e de resposta (TUFEKCI e WALLACE, 1998; ROCHA; 2006), a literatura sociológica frisa a necessidade de extrapolar o tecnicismo e incorporar a dinâmica social e política da produção de desastre. A própria concepção de desastre seria um fenômeno social, a partir de eventos que rompem a estrutura social e afetam principalmente grupos minoritários e socialmente vulneráveis (VALÊNCIO, 2010). Nessa abordagem o desastre pode ser relacionado a fenômenos naturais, mas substancialmente é um fenômeno social, uma escolha de trajetória da sociedade em sua direção (KELMAN, 2020). Nesse sentido, na modernidade os perigos de um desastrejá não mais derivam da natureza (GIDDENS, 1991), mas são reificados através da intensificação dos modelos tecnocráticos pautados no modelo reativo e no mapeamento de riscos dos fenômenos naturais (VALENCIO et al., 2004).

A compreensão do desastre não deriva, no entanto, apenas do "fator antrópico", uma vez que esse oculta a complexidade, as diversidades, as contradições sociais e os conflitos entre classes, etnias e grupos sociais. É necessário expor tais questões, abordando as assimetrias na distribuição de renda, riscos e prejuízos, além da heterogeneidade de agentes, responsabilidades e variáveis de influência (SOUZA, 2015).

Chega-se aqui a uma concepção fundamental para a compreensão dos desastres, que é a vulnerabilidade. Nesse caso, as contribuições de Daniel Hogan foram de grande importância, passando pela argumentação em prol de seu uso na compreensão da segurança humana no debate das mudanças ambientais globais (HOGAN, 2001), da centralidade da vulnerabilidade na compreensão dos desastres e nas relações ambiente e população (HOGAN, 2005) e no debate mais consolidado da interdisciplinaridade da vulnerabilidade (HOGAN e MARANDOLA Jr., 2005; MARANDOLA JR. e HOGAN, 2007). Principalmente em conjunto com Eduardo Marandola Júnior, seu então orientando no 
doutorado em Geografia, Hogan contribuiu para a disseminação do debate teórico e empírico da vulnerabilidade, em que tal concepção, assim como a de risco, é plural, realizada com múltiplos sentidos e usos. Mais especificamente, o pesquisador foi um dos articuladores da consolidação de uma interface das pesquisas relativas à vulnerabilidade de lugares e de populações em relação aos riscos considerando que as dinâmicas socioespaciais, assim como da relação natureza e sociedade, são fundamentais para que se compreendam o conjunto de condições em que se constrói a vulnerabilidade, ou seja, as (in) capacidades nas respostas, ajustes e mitigação de perigos (MARANDOLA JR. E HOGAN, 2005).

Nesse sentido vulnerabilidade e risco são absolutamente indissociáveis: a existência do risco pressupõe certa vulnerabilidade, e a concretização de perigos associados aos riscos é relacional ao nível de vulnerabilidade (FREITAS e CUNHA, 2013). A vulnerabilidade é intrinsicamente relacionada à exposição ao risco, e desse modo, a questão da produção social dos riscos e das desigualdades de espaços vulneráveis é fundamental.

Tem-se aqui a ascensão da concepção de justiça ambiental, onde risco e a vulnerabilidade podem ser agravadas não só pela pobreza estrutural, mas principalmente pela injustiça social (VALENCIO, 2010). A concepção, ao destacar a "territorialização injusta", enfatiza as desigualdades e os relativos processos históricos discriminatórios contra determinados grupos, que são agravados por discursos tecnocráticos que desqualificam continuamente os sujeitos vulneráveis. Adicionalmente, as práticas tecnocratas estatais tendem a apontar os desastres como obra de escolhas individuais, desconsiderando o processo de produção de vítimas de uma proteção desigual e invisibilizando as desigualdades dos mecanismos de produção de capacidades de autoproteção (tanto via influência nos processos decisórios como no controle do mercado das localizações) (ACSELRAD, 2006).

No território, portanto, são materializadas dinâmicas em que as forças de mercado e práticas discriminatórias das agências de governo contribuem de forma articulada para a produção das desigualdades ambientais. Há uma viabilização desigual dos 
riscos, com relativo enfraquecimento político dos grupos sociais residentes em áreas de riscos, usualmente vistos como carentes de conhecimento e sem preocupações ambientais. Assim, problemas ambientais são indissociáveis da forma com que os recursos políticos, materiais e simbólicos são distribuídos, resultando em formas simultâneas de opressão e decorrentes injustiças ambientais (ACSELRAD, 2002).

Na perspectiva da justiça ambiental a atual associação mercado-Estado não atua como instrumento de superação da desigualdade social e ambiental (ACSELRAD, 2002). Inserida na dinâmica do mercado de terras, o acesso à habitação segue assim uma lógica produtiva e mercantil especulativa, com custos de habitação inviáveis entre os mais pobres, com uma desigualdade distributiva que aprofunda problemas fundiários. Por sua vez esses são pouco compreendidos na pura cartografização da vulnerabilidade, uma vez que prescindem da necessária visão sócio-histórica, dinâmica e relacional (VALENCIO, 2010).

Em termos sintéticos, tem-se assim uma concepção que compreende o desastre enquanto produto da complexa relação entre dinâmicas naturais e sociais, mas na qual sua ocorrência e interpretação dependente das relações sociais, de poder e do processo histórico. Em tal compreensão a vulnerabilidade seria um conceito chave, relacionada às condições e disposições da população nas suas capacidades de responder ao desastre, conectada a intensidade pela qual estas foram impactadas. Por fim, a ótica da justiça ambiental propicia um diálogo com os processos de vulnerabilização e distribuição desigual dos riscos, com desproporcionalidade de consequências ambientais negativas (nesse caso, desastres) dentre os grupos sociais. 
$|8|$

Desastres e vulnerabilidade...

\section{O "desastre" da RSRJ em 2011}

A RSRJ está localizada na região central do Estado, ao norte da Região Metropolitana do Rio de Janeiro. Historicamente sua ocupação foi relacionada aos ciclos de ouro, café e à presença da família imperial no período do Brasil Colônia, tendo hoje o turismo e agricultura como principais atividades econômicas.

Em 2011, entre os dias 11 e 12 de janeiro, a RSRJ teve uma precipitação acumulada de $241,8 \mathrm{~mm}$, sendo que nos primeiros 12 dias do ano o total foi de 573,6mm (DOURADO, et al, 2012). Sua paisagem foi profundamente alterada em poucas horas, com retilineamento de corpos hídricos, desaparecimento de ilhas fluviais e desmoronamentos que acarretaram a retirada da camada vegetal e destruição de infraestruturas, como pontes, estradas, residências e plantações (ALERJ, 2011; BANCO MUNDIAL, 2012).

As estatísticas do desastre estimam um total de 916 mortos, 2.351 feridos, 22.479 desalojados, 16.458 desabrigados e 304.5062 pessoas afetados direta e indiretamente nos sete municípios mais afetados (Tabela 1) (ALERJ, 2011; BANCO MUNDIAL; 2012). Nova Friburgo e Teresópolis concentraram a maior parte dos óbitos, sendo que o primeiro teve quase toda a população - cerca de $98 \%$, de alguma forma afetada ${ }^{3}$.

\footnotetext{
${ }^{3}$ Os números oficiais são questionados por entidades da organização civil. Como exemplo, o Centro de Defesa dos Direitos Humanos (CDDH) de Petrópolis aponta um valor de ao menos 10 vezes sobre o número oficial de mortos. No caso, como a morte é um ato jurídico, no caso de famílias inteiras que viessem a óbito não houve quem 'pleiteasse' os corpos (CANEJO, 2015).
} 
Tabela 1. Dados populacionais e estimativas do desastre na RSRJ, 2011

\begin{tabular}{|c|c|c|c|c|c|c|}
\hline Municípios & $\begin{array}{c}\text { População } \\
\mathbf{( 2 0 1 0 )}\end{array}$ & Afetados & Desabrigados & Desalojados & Mortos & Feridos \\
\hline Areal & 11.423 & 7.000 & 1.469 & 1.031 & 0 & 15 \\
\hline Bom jardim & 25.333 & 12.380 & 632 & 1.186 & 2 & 423 \\
\hline $\begin{array}{c}\text { Nova } \\
\text { Friburgo }\end{array}$ & 182.082 & 180.000 & 3.800 & 4.500 & 428 & 900 \\
\hline Petrópolis & 295.917 & 19.000 & 2.800 & 6.341 & 74 & 0 \\
\hline $\begin{array}{c}\text { São José do } \\
\text { Vale do Rio } \\
\text { Preto }\end{array}$ & 20.251 & 20.682 & 790 & 0 & 4 & 163 \\
\hline Sumidouro & 14.900 & 15.000 & 240 & 311 & 22 & 13 \\
\hline Teresópolis & 163.746 & 50.500 & 6.727 & 9.110 & 386 & 837 \\
\hline Total & $\mathbf{7 1 3 . 6 5 2}$ & $\mathbf{3 0 4 . 5 6 2}$ & $\mathbf{1 6 . 4 5 8}$ & $\mathbf{2 2 . 4 7 9}$ & $\mathbf{9 1 6}$ & $\mathbf{2 . 3 5 1}$ \\
\hline
\end{tabular}

Fonte: Adaptado de ALERJ (2011) e BANCO MUNDIAL (2012)

A extensa bibliografia sobre esse desastre traz um certo consenso em relação aos seus fatores determinantes. Mais do que a simples combinação entre alta pluviometria, ocorrência de movimentos de massa e inundações, os desdobramentos dos eventos de tais dias são entendidos como um fenômeno de progressão da vulnerabilidade, com base em causas de fundo (estruturas socioeconômicas e históricas), que influenciam pressões dinâmicas (como mudanças populacionais, urbanas e de legislação ambiental) e criam condições inseguras de habitação. No encontro com o perigo se construiu o desastre (MARCHEZINI e WISNER, 2017). A compreensão do fenômeno como um desastre perpassa, portanto, tanto o evento meteorológico associado às características geoambientais da região como as questões relacionadas ao seu histórico de ocupação, dinâmicas socioeconômicas, ordenamento territorial, políticas de uso de solo e políticas relacionadas à gestão do risco de desastre (PORTELLA e NUNES, 2014). O desastre de 2011 só o foi em função dos processos sociais e vulnerabilidades que criaram as condições para sua ocorrência, em um fenômeno 
que não pode ser circunscrito ao "dia do desastre", mas sim aos padrões mais amplos de desenvolvimento e vulnerabilização (FREITAS et al., 2012). Assim, tal qual argumentado por Hogan (2005), a necessidade de compreender as múltiplas vulnerabilidades dos grupos sociais e as decorrentes desigualdades dos impactos ambientais foi confirmada no caso da RSRJ. Tais questões serão retomadas na análise empírica do risco na região.

Contudo, não há um mapeamento dos locais e/ou populações efetivamente atingidas, dificultando análises feitas posteriormente ao desastre a partir das concepções de justiça ambiental e vulnerabilidade. Para contornar tais questões a pesquisa incluiu as fontes de dados e métodos descritos na seção seguinte.

\subsection{Fonte de dados e métodos}

A análise quantitativa do trabalho foi feita a partir do Censo Demográfico 2010 e da Base Territorial Estatística de Áreas de Risco - BATER, que foi desenvolvida pela parceria entre o Centro Nacional de Monitoramento e Alertas de Desastres Naturais (Cemaden) e o Instituto Brasileiro de Geografia e Estatística (IBGE). Nesta foi feito o mapeamento das áreas de risco e das respectivas populações que ali habitam, segundo as informações coletadas no Censo Demográfico de 2010 (Dias et al., 2018).

Optou-se pelo uso da BATER por três questões: devido à ausência de mapeamento e de registros realizados pela Defesa Civil e/ou outros órgãos públicos das áreas efetivamente afetadas pelo desastre em janeiro de 2011 que incluam dados sociodemográficos, pelo próprio projeto ter utilizado como área piloto três dos municípios da RSRJ atingidos pelo desastre em 2011 - Petrópolis, Teresópolis e Nova Friburgo, e pela sua possibilidade de uso em casos em uma diversidade ampla de municípios em todo o Brasil, possibilitando a análise de características e condições de habitação da população residente nestas áreas. Atualmente a base cobre 872 municípios do país. Além de tais questões, ressalta-se que a BATER traz o mapeamento das populações em áreas de risco em 2010, com 
dados relativos ao ano imediatamente anterior à 2011, sendo um cenário base da sua ocorrência.

Um segundo procedimento adotado foi a realização de entrevistas semiestruturadas, considerando a participação dos órgãos públicos e a percepção quanto sua efetividade no desastre, e a compreensão do impacto do evento em si. Essas foram realizadas em Nova Friburgo e Teresópolis, ao longo dos meses de novembro e dezembro de 2019.

Ao todo, foram realizadas onze entrevistas, além de visitações em algumas das áreas atingidas pelo desastre.

As entrevistas seguiram o método de amostragem em cadeia não probabilística do método Bola de Neve. A escolha dos entrevistados se deu pela indicação de perfis de entrevistados com vivência do desastre, com indicações subsequentes.

Em Teresópolis, iniciou-se contato com servidores na sede do Parque Nacional da Serra dos Órgãos (PARNASO) que indicaram outros potenciais entrevistados seguindo perfis de interesse (jornalistas, bombeiros que atuaram no resgate, presidentes de associações, moradores realocados e vizinhos voluntários no resgate). As entrevistas realizadas em Teresópolis foram:

- 2 ex-moradoras do bairro Caleme, que descreveram sobre o evento e foram realocadas para o condomínio Fazenda Ermitage, construído pelo programa Minha Casa, Minha Vida e destinado integralmente às vítimas deste desastre.

- 1 Entrevista com testemunha ocular do evento no bairro Caleme, que participa da Associação de Moradores e foi um dos primeiros voluntários do bairro durante o resgate.

- 1 responsável pelo recenseamento da população atingida pela Hollus Engenharia para o levantamento das indenizações.

- 1 Servidora da Secretaria Municipal de Desenvolvimento Social e moradora do bairro Campo Grande, também atingido.

Em Nova Friburgo, foram entrevistados:

- 1 Secretário da Defesa Civil Municipal.

- 1 Bombeiro e líder comunitário que participou da resposta ao desastre, inicialmente como voluntário enquanto ocorria o evento e posteriormente de forma institucional pela corporação. 
- 1 ex-membro da comissão brasileira no Programa das Nações Unidas para o Meio Ambiente e organizador da Rio 92.

- 1 frei, que a época do desastre se encontrava alocado em bairros vizinhos aos atingidos, e que atuou no atendimento aos atingidos e na mobilização após o evento.

- 1 participante do grupo Resgate da Cidadania e da Associação das Vítimas da Tragédia (AVIT), que detalhou o histórico de desastres e o impacto na produção de desigualdade na Região Serrana.

- 1 pesquisador da Fiocruz que discorreu sobre as pesquisas nas áreas atingidas e detalhou trabalhos com a população local pós-desastre.

\subsection{Vulnerabilidade e risco na RSRJ}

De acordo com o BATER, em 2010 estimava-se que as áreas de risco concentravam ao menos 61.778 domicílios e 168.244 pessoas, representando cerca de $23,6 \%$ da população dos munícipios mais afetados pelo desastre da RSRJ (Tabela 2). O município de Petrópolis possuía o maior quantitativo populacional, e, Areal, o maior percentual. Proporcionalmente havia mais domicílios em áreas de risco em relação a população, o que é explicado pela existência de domicílios vagos (cerca de 12,5\% do total de domicílios em áreas de risco). 
Tabela 2. População e domicílios em áreas de risco, RSRJ, 2010.

\begin{tabular}{|c|c|c|c|c|c|c|}
\hline \multirow{2}{*}{ Municípios } & \multicolumn{3}{|c|}{ População } & \multicolumn{3}{c|}{ Domicílios permanentes } \\
\cline { 2 - 7 } & Total & $\begin{array}{c}\text { Em área } \\
\text { de Risco }\end{array}$ & $\begin{array}{c}\text { \% em } \\
\text { área de } \\
\text { Risco }\end{array}$ & Total & $\begin{array}{c}\text { Em área de } \\
\text { Risco }\end{array}$ & $\begin{array}{c}\text { \% em área } \\
\text { de Risco }\end{array}$ \\
\hline Areal & 11.423 & 5.036 & 44,09 & 3.500 & 1.705 & 48,71 \\
\hline Bom Jardim & 25.333 & 5.444 & 21,49 & 8.463 & 2.023 & 23,90 \\
\hline $\begin{array}{c}\text { Nova } \\
\text { Friburgo }\end{array}$ & 182.082 & 33.660 & 18,49 & 63.530 & 13.293 & 20,92 \\
\hline Petrópolis & 295.917 & 72.070 & 24,35 & 96.319 & 24.089 & 25,01 \\
\hline $\begin{array}{c}\text { São José do } \\
\text { Vale do Rio } \\
\text { Preto }\end{array}$ & 20.251 & 3.881 & 19,16 & 6.501 & 1.515 & 23,30 \\
\hline Sumidouro & 14.900 & 2.381 & 15,98 & 5.073 & 925 & 18,23 \\
\hline Teresópolis & 163.746 & 45.772 & 27,95 & 53.782 & 18.228 & 33,89 \\
\hline TOTAL & 713.652 & 168.244 & 23,58 & 237.168 & 61.778 & 26,05 \\
\hline
\end{tabular}

Fonte: BATER, IBGE/CEMADEN

Gráfico 1. Percentual de moradores em área de risco por rendimento nominal mensal domiciliar per capita (em Salário Mínimo), 2010.

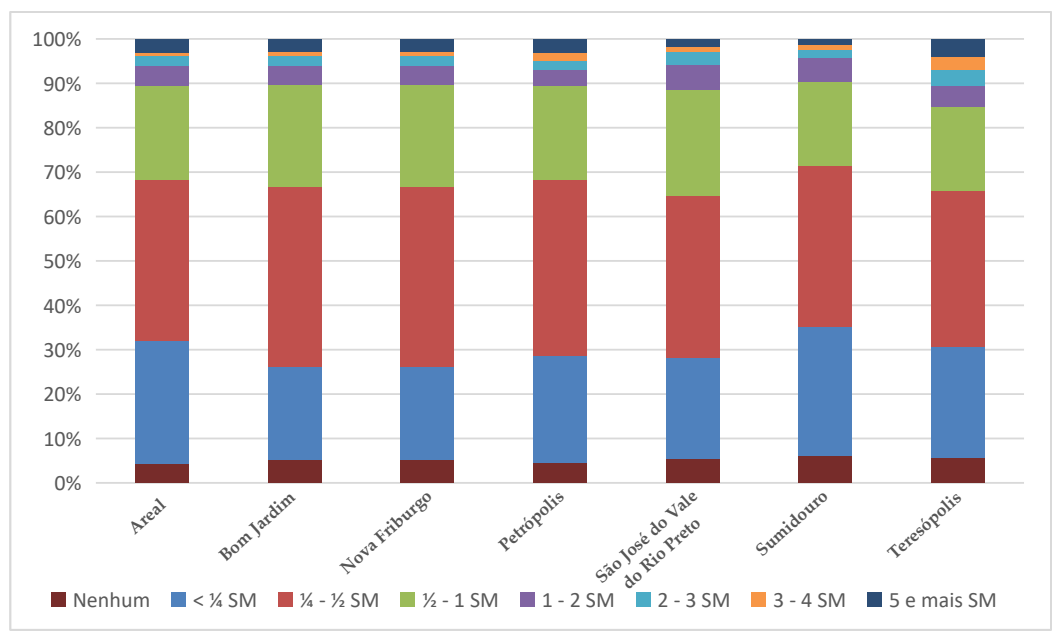

Fonte: BATER, IBGE/CEMADEN 
Nessas áreas o rendimento nominal domiciliar per capita (Gráfico 1) se concentrou em valores inferiores a um salário mínimo (cerca de $83 \%$ ), sendo que em mais da metade destes o rendimento foi de até meio salário mínimo. Além disso, o grupo que não teve ganhos mensais era equivalente ao grupo de maior renda (acima de três salários mínimos).

Em termos da distribuição etária (Gráfico 2), a população em área de risco é composta predominantemente por aquela em idade economicamente ativa - entre 15 e 59 anos - com cerca de $65 \%$ da população. O percentual de idosos apresentou pequena variação, concentrando entre 11 e $12 \%$ da população. Lembra-se que a população de crianças e idosa está entre as mais vulneráveis, por sua maior exposição, dependência e limitação de locomoção (MORROW, 1999; PHILLIPS et al., 2010; FREITAS e CUNHA, 2013; AVILA e MATTEDI, 2017).

Gráfico 2. Percentual da população em áreas de risco por grupos de idade (em grupos etários), RSRJ, 2010.

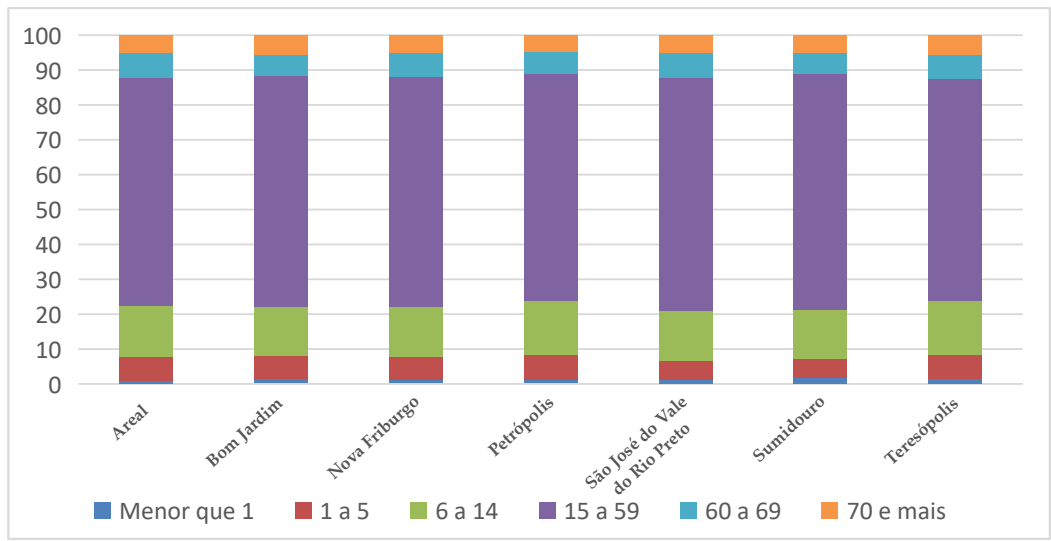

Fonte: BATER, IBGE/CEMADEN

Além disso, nesses municípios a população, em sua maioria, residia em apartamentos $(87,26 \%)$, com elevada concentração de domicílios próprios em aquisição (63,24\%). Embora tais percen- 
tuais não se refiram aos imóveis formalizados com registro, é importante observar que uma constatação em campo foi de que moradores sem a propriedade do imóvel atingido não tiveram direito à indenização, não podendo concorrer ao recebimento do aluguel social.

A BATER também disponibiliza os mapeamentos das áreas de risco, que revelam os padrões entre assentamentos, riscos e o relevo da região. Nas Figuras 1 e 2, que trazem Areal, São José do Vale do Rio Preto, Bom Jardim e Sumidouro, a concentração das áreas de risco ocorre ao longo do canal fluvial. Apesar de um número reduzido de vítimas fatais em comparação aos outros municípios, nesses houve um número considerável de danos e atingidos, principalmente nas áreas de várzea ocupadas ao longo dos cursos hídricos. Nessas localidades os trajetos de rodovias permeiam o leito dos principais rios, potencializando a condição de vulnerabilidade dessas populações dado o assoreamento do canal fluvial decorrentes da pavimentação e da constituição de assentamentos urbanos. Além disso, em Bom Jardim e Sumidouro as populações em área de risco também estão em pequenas manchas urbanas afastadas. 
$|16|$

Desastres e vulnerabilidade...

Figura 1. Mapa de localização das áreas de riscos no município de Areal e São José do Vale do Rio Preto (2010).

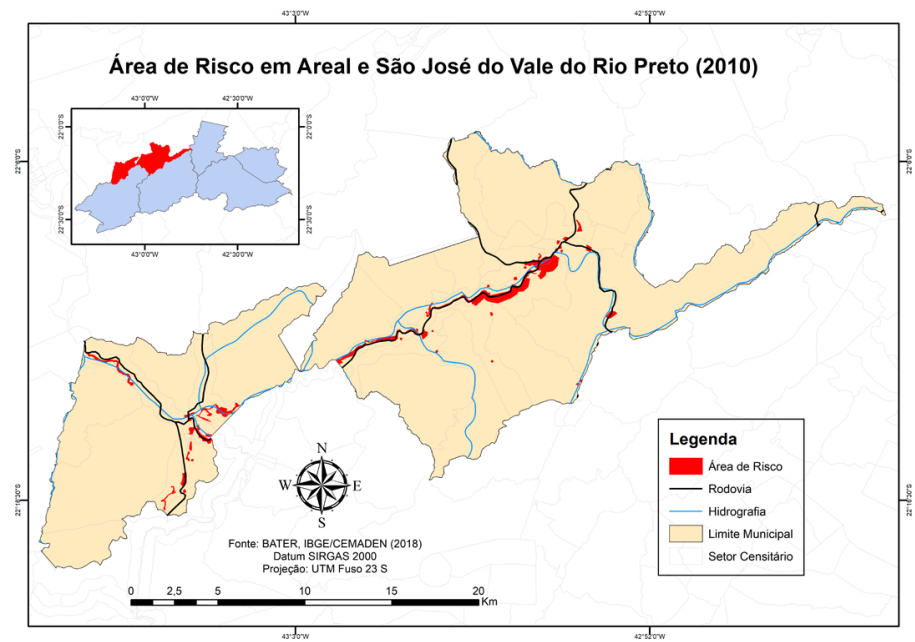

Fonte: BATER, IBGE/CEMADEN

Figura 2. Mapa de localização das áreas de riscos no município de Bom Jardim e Sumidouro (2010).

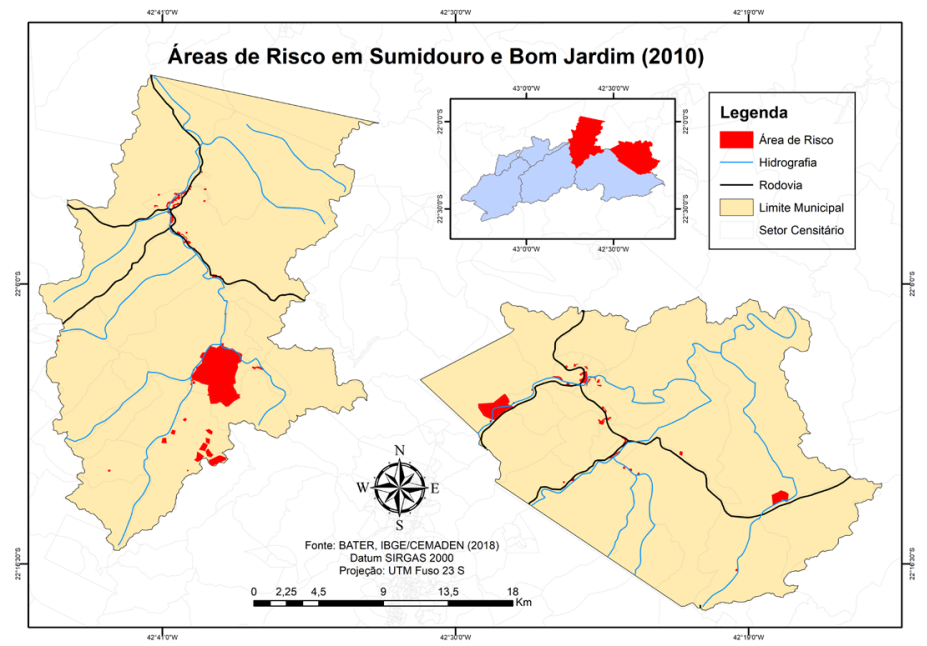

Fonte: BATER, IBGE/CEMADEN

Idéias, Campinas, SP, v.12, 01-29, e021019, 2021 
Em Petrópolis (Figura 3), as áreas de riscos se concentram na área central e mais urbanizada, recortada por uma complexa hidrografia e relevos fortemente acidentados. Além disso, a população rural da localidade também esteve sujeita a risco e foi severamente afetada em 2011.

Figura 3. Mapa de localização das áreas de riscos no município de Petrópolis (2010).

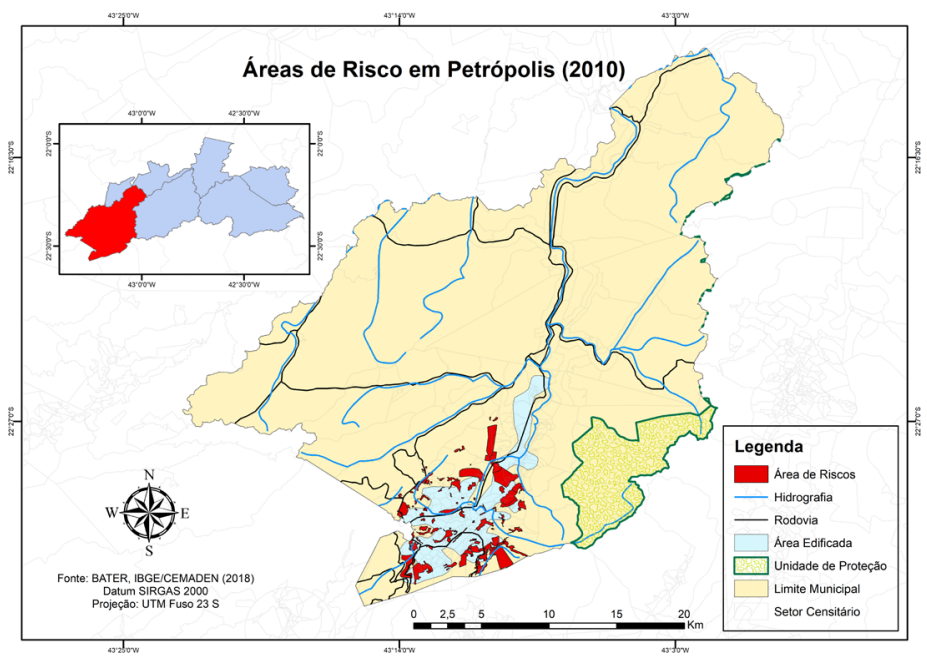

Fonte: BATER, IBGE/CEMADEN 
Desastres e vulnerabilidade..

Figura 4. Mapa de localização das áreas de riscos no município de Teresópolis (2010).

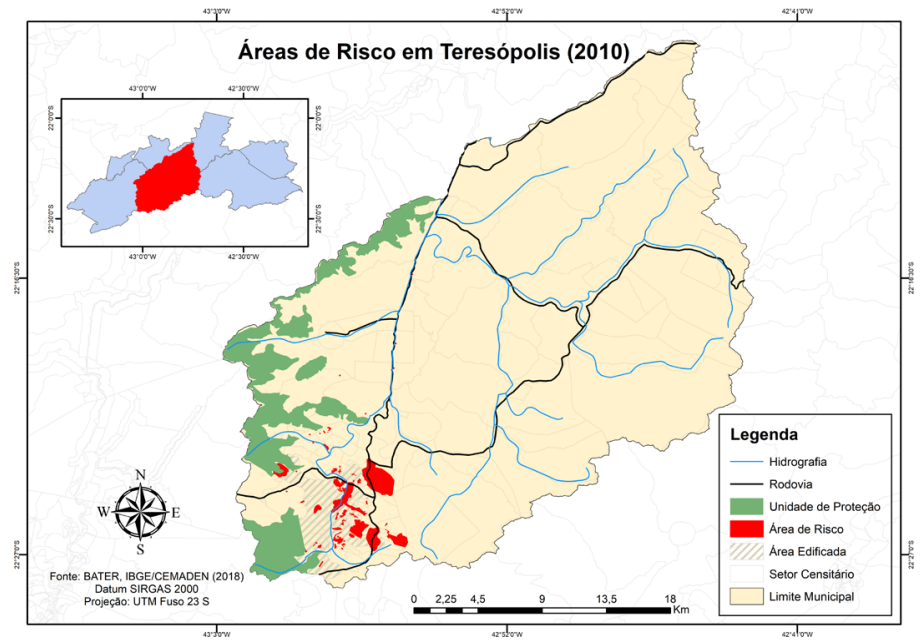

Fonte: BATER, IBGE/CEMADEN

Figura 5. Mapa de localização das áreas de riscos no município de Nova Friburgo (2010).

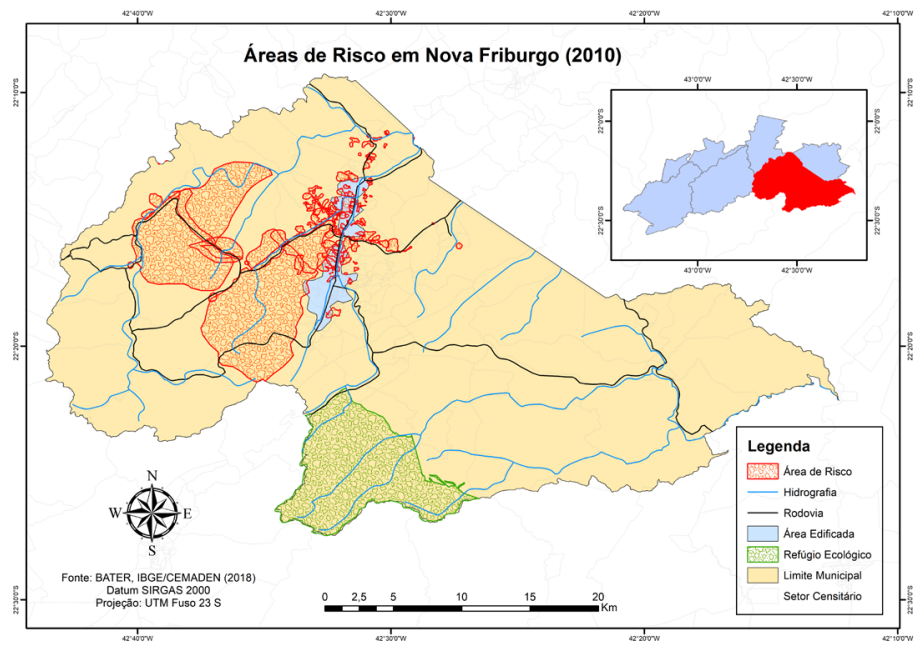

Fonte: BATER, IBGE/CEMADEN 
Juntamente com Petrópolis, Teresópolis (Figura 4) e Nova Friburgo (Figura 5) são conhecidos pelo seu relevo, parques naturais e áreas de preservação, que, teoricamente, acarretariam maior preservação da vegetação e estabilidade do terreno $(\mathrm{BUSCH}$ e AMORIM, 2013), com impedimento legal do uso dessas áreas e seu entorno para ocupação.

Somente em Teresópolis tem-se áreas de risco próximas ao Parque Nacional Serra dos Órgãos, ao Parque Estadual dos Três Picos e Parque Natural Municipal Montanhas de Teresópolis. Os motivos principais para tal são a proximidade destes ao centro urbano e seu histórico de criação conflituoso, com ocupações em suas áreas de amortização. Assim, em Teresópolis também são existentes áreas de risco mais próximas ao centro urbano do município, caracterizado pelo relevo acidentado e presença marcante da hidrografia e malha viária paralela.

Teresópolis e Nova Friburgo foram os dois municípios mais fortemente atingidos durante 2011, com características muito semelhantes em relação processo de urbanização, hidrografia e relevo. Quanto à dinâmica dos eventos, ambos possuem recorrentes enchentes e deslizamentos. Este último, no entanto, possui grandes manchas de área de risco na cidade, mas principalmente em seu entorno, em áreas rurais ou pouco urbanizadas, como pode-se observar nos relatos de campo explorados a seguir.

\subsection{Relatos de campo e o desastre}

Uma das dinâmicas centrais no desastre de 2011 foi o despreparo na resposta do poder público, que ocorreu com a mobilização de recursos materiais e ações de forma improvisada, dependentes de colaborações espontâneas, de forma militarizada e com participação de diferentes esferas de governo. Se, principalmente dada a presença da esfera federal as respostas permitiram a presença de um componente técnico-científico, esse foi imparcial, com insuficiente conhecimento sobre o território local, falta de diálogo com residentes e com uma dinâmica assimétrica entre os saberes, onde moradores tornaram-se objetos de intervenção 
não-participativos (PORTELLA e OLIVEIRA, 2017). Houve supervalorização do modelo tecnicista-reativo, com diálogo deficiente e hierarquizado em um jogo assimétrico de linguagem, justificando interdições e remoções, que, para a "preservação dos afetados", violou direitos em um arranjo de crueldade institucional (PORTELLA e OLIVEIRA, 2017; VALENCIO, 2010).

Os relatos de campo confirmaram tais processos, com desconfiança dos gestores por parte da população, estabelecimentos posteriores de canais próprios de alerta e abandono de práticas "oficiais", como simulações de desastre. Tais questões são notadas em áreas intensamente afetadas em 2011, como o condomínio Fazenda Ermitage e o bairro Caleme, em Teresópolis (localizados entre o Parque Nacional e o Parque Municipal). No primeiro observam-se demandas ainda existentes de acompanhamento psicológico dos sobreviventes do desastre, além de exposição a novos riscos e inexistência de sistemas de alerta. Já no segundo, que conta com sistema de alerta sonoro, forte mobilização social e iniciativas para mapear a recuperação da comunidade e suas áreas vulneráveis, foi relatado que serviços básicos não foram normalizados no pós 2011: ruas de acesso permanecem interditadas, serviços de transporte público limitados e construções abandonadas.

No bairro Córrego D’antas, em Nova Friburgo, foi relatado que, a despeito da falta de diálogo entre Defesa Civil e população e diferentes percepções de risco, após o desastre houve uma aproximação comunitária que fortaleceu a associação de moradores e permitiu a criação de ações locais para a diminuição das vulnerabilidades. Dentre essas estão reinvindicações socioambientais para o bairro, uso de redes sociais para alertas de moradores sobre a ocorrência de chuvas, além de iniciativas institucionalizadas, como a parceria com o Laboratório de Geohidroecologia da UFRJ e a decorrente Rede para a Gestão de Risco da Bacia do Córrego Dantas.

Durante os trabalhos de campo também foi relatado o uso o Decreto Estadual 32.081/2010 - o mesmo utilizado para remoções em decorrência de megaeventos - para legitimar a remoção de pessoas em áreas de risco, além de negociações individuais para 
a desmobilização das pessoas. Segundo o relato, esta remoção foi utilizada para a construção do Parque Fluvial de Nova Friburgo (Projeto Rios da Serra).

Formou-se assim um conjunto de ações em que a população foi desapropriada de sua capacidade em lidar com a experiência do desastre, com o conhecimento comunitário e local extraído e impessoalizado sob a forma de relatórios e registros técnicocientíficos (PORTELLA E NUNES, 2014).

De modo geral, a RSRJ é recorrentemente afetada por eventos hidrometeorológicos considerados extremos, em um contexto em que a desigualdade também se expressa na distribuição dos riscos. Dada tal assimetria, com uma parcela da população ocupando áreas mais privilegiadas e seguras, as condições de risco e maior vulnerabilidade são concentradas em populações específicas que experenciam os desastres com poucas possibilidades de escape. Tal caso evidencia a importância de aproximar diferentes tradições na abordagem de risco e vulnerabilidade, tal qual apontado por Marandola Jr e Hogan (2005), compreendendo, por um lado, as dinâmicas das populações em situações de risco e a vulnerabilidade sociodemográfica, e por outro, incorporando as reflexões sobre perigos e o espaço, tais quais focadas pela geografia.

É nesse sentido que se considera que o alcance da resiliência na região, especialmente nas áreas de risco e encostas urbanas, depende de múltiplos fatores, como a manutenção de APPs e espaços livres, da criação de parâmetros legais adequados, da regulação urbana e também da própria superação da mercantilização das cidades e regulação do mercado de moradias (SCHLEE, 2013). Esse, com custos de habitação inalcançáveis para a maior parte da população, fomenta a ocupação de áreas degradadas e suscetíveis à desastres. O resultado dessa dinâmica é o silenciamento e a invisibilização de processos relacionais, onde as consequências dos eventos-extremos não decorrem da imprevisibilidade dos fenômenos, mas de sua distribuição entre populações, classes sociais e comunidades (ACSELRAD, 2002; PORTELLA e NUNES, 2014). 
|22|

Desastres e vulnerabilidade...

Confirmado em campo, um aspecto que potencializa tais processos foi a permanência do caráter ainda combativo dos discursos de respostas aos desastres em detrimento às ações preventivas. Isso pode ser exemplificado no foco das ações de Defesas Civis, que atuam em programas de resposta, como na instalação de avisos sonoros. Com um entendimento do desastre como resultado de fenômenos ambientais isolados, pouco se aborda o processo histórico da distribuição desigual da vulnerabilidade, além de nulas ou pouco efetivas medidas de diminuição dos riscos (VALENCIO, 2014).

Do ponto de vista habitacional, as iniciativas pós-2011 passaram a priorizar o atendimento dos afetados pelo desastre através do programa "Minha Casa, Minha Vida". Contudo, considerando a elevada frequência de incidentes relacionados à chuvas na RSRJ, tais programas atendem vítimas de diferentes eventos, como ressaltado em entrevistas entre membros do grupo Resgate da Cidadania, criado a partir do fim da Associação das Vítimas da Tragédia (AVIT), e da Comissão das Vítimas da Tragédia da Região Serrana, composta pela articulação de representantes de municípios atingidos em 2011.

Duas questões emergem desse quadro. A primeira diz respeito as irregularidades na concessão das unidades habitacionais apontadas durante as entrevistas. Nesse caso, argumentavase que beneficiários não prioritários ou não atingidos eram contemplados e a existência de problemas estruturais na construção dos condomínios. A segunda questão diz respeito a estratégia das políticas habitacionais usuais, como o MCMV. Essas, combinadas com as políticas de recuperação de desastres, acirraram vulnerabilidades anteriores, apenas com seu deslocamento e concentração, confirmando o desastre como um processo social e histórico de maior duração (PORTELLA e OLIVEIRA, 2017) e a vulnerabilidade como fenômeno intrinsecamente atrelado ao contexto geográfico, da produção social dos perigos e dos sistemas de proteção e insegurança (MARANDOLA Jr. e HOGAN, 2005).

Há tanto a territorialização injusta (VALENCIO, 2010) como a viabilização desigual dos riscos (ACSELRAD, 2002). Diferentes 
depoimentos colhidos em campo abordaram as circunstâncias nãosatisfatórias dos empreendimentos, com reprodução de condições de risco e vulnerabilidade. Confirma-se uma "biopolítica do desastre", operacionalizada através de técnicas que no momento do evento extremo fazem viver e que, após sua ocorrência, deixam morrer, dada a desconexão de necessidades e demandas sociais de reconstrução (MARCHEZINI, 2014).

Essa dinâmica pode ser exemplificada pelos deslizamentos e posterior retirada temporária da população no bairro Caleme, em Teresópolis. Neste, após a liberação de algumas casas, os moradores se depararam com outras pessoas habitando suas residências; além de ocupantes de casas permanentemente interditadas. Devido à retirada de parte da população e os danos causados pelo evento, o bairro - residencial e historicamente ocupado por um pequeno número de famílias - passou a sofrer com forte desvalorização no preço da terra. Foi então que, meses depois, houve novo aumento da sua população, com novas ocupações em encostas íngremes, leitos de rio e no próprio curso do rio.

Há ainda um sentimento generalizado de desconfiança com os órgãos públicos por parte da população, sendo que a série de mapeamentos sem resultados concretos aos olhos da população e a interdição e desinterdição das moradias favoreceram as dúvidas sobre a competência e preparo da gestão. Ademais, há percepção de que as decisões de interdições e indenizações são arbitrárias e sem critérios, potencializando a falta de articulação para a governança, com remoções que não garantiram o deslocamento para um lugar seguro e de qualidade e tão pouco o recebimento de aluguel social.

\section{Considerações finais}

O desastre de 2011 na RSRJ pode ser compreendido como um processo multidimensional, afetando dinâmicas sociais, econômicas, ambientais e político-institucionais. Além de ter estimulado pesquisas e a literatura sobre o tema, também influenciou alterações na legislação e gestão de risco de desastres, ainda que essas sejam comumente criticadas. São exemplos a Lei 
no 12.608/2012, com o Estatuto de Proteção e Defesa Civil, o Plano Nacional de Gestão de Riscos e Resposta a Desastres Naturais, a Política Nacional de Proteção e Defesa Civil e a criação do CEMADEN.

Apesar da alta pluviometria, foi na complexa relação sociedade e natureza que o desastre se materializou. Esse artigo visou contribuir para a compreensão de tal fenômeno mobilizando conhecimentos sobre riscos e vulnerabilidades do lugar e populacionais, ressaltando aspectos construídos na obra de Daniel Hogan, juntamente a aspectos sociológicos sobre os desastres, como apontados por Henri Acselrad e Norma Valêncio, dentre outros. Especificamente, ressalta-se que as contribuições de Daniel Hogan na compreensão e disseminação de uma perspectiva da vulnerabilidade que contemple a dinâmica sociedade natureza permanece, ainda mais na contemporaneidade. Nessa, as desigualdades persistentes, os processos de vulnerabilização e as incertezas sobre eventos extremos são elementos presentes não só na RSRJ, mas relacionados a dinâmica de um padrão de desenvolvimento mais amplo, que impossibilita o alcance da sustentabilidade e da segurança humana em um contexto de produção e reprodução de desastres.

No caso da RSRJ, as dinâmicas climáticas e geomorfológicas são inerentes aos ciclos naturais, mas se manifestam nas condições materiais, no processo histórico e nas assimetrias de poder que determinam os grupos vitimados. Ainda, para além do impacto social do desastre específico, esta é uma questão rotineira na região, com sucessivas tragédias que atingem, principalmente, a população com menor renda.

Em campo, cerca de dez anos após o sucedido, se presenciam áreas urbanas não reconstruídas e áreas verdes não recuperadas. A participação estatal, muitas vezes pontual, foi recorrentemente apontada pelos entrevistados como ineficiente ou inexistente, afetando a continuidade de demanda habitacional em locais seguros, a persistência dos traumas psicológicos e a reprodução da desigualdade. 
A luz das discussões sobre vulnerabilização e justiça ambiental, evidencia-se como a organização do espaço orienta a criação de territórios injustos e desiguais de reprodução de exposição ao risco, com a intensificação da vulnerabilidade e exclusão à segurança de um modo mais amplo.

Desta forma, o desastre se dá pela produção e reprodução - social e territorial - da desigualdade, distribuindo de forma assimétrica a exposição, a probabilidade e a capacidade de resposta e adaptação. O perfil populacional em áreas de riscos na RSRJ é claro deste cenário: majoritariamente composto por pessoas de baixa renda, em idade economicamente ativa e em edifícios expostos à ocorrência de enchentes e deslizamentos.

\section{Referências}

ACSELRAD, Henry. Justiça ambiental e construção social do risco. Desenvolvimento e meio ambiente, v. 5, 2002.

ACSELRAD, Henry. Vulnerabilidade ambiental, processos e relações. Comunicação ao II Encontro Nacional de Produtores e Usuários de Informações Sociais, Econômicas e Territoriais, FIBGE, Rio de Janeiro, v. 25, 2006.

\section{ALERJ. Resolução № 09/2011; Comissão Parlamentar De Inquérito. RELATÓRIO FINAL, 261p. 2011.}

BANCO MUNDIAL. Avaliação de perdas e danos: inundações e deslizamentos na Região Serrana do Rio de Janeiro. Relatório elaborado pelo Banco Mundial com apoio do Governo do Estado do Rio de Janeiro. Brasília, 2012. Disponível em: http://www.mi. gov.br/pt/c/document_library/get_file?uuid=74dde46c-544a-4bc4a6e1-852d4c09be0 6\&groupId=10157. Acesso em: 2 jun. 2019.

BUSCH, Amarílis; AMORIM, Sônia. A tragédia da região serrana do Rio de Janeiro em 2011: procurando respostas. ENAP: Casoteca de Gestão Pública. 2013. 
CANEJO, A. № de vítimas em tragédia no RJ pode ser 10 vezes maior, dizem entidades. G1. 2015. Disponível em: http://g1.globo. $\mathrm{com} / \mathrm{rj} /$ regiao-serrana/noticia/2015/08/entidades-apontamsubnotificacao-de-vitimas-da-tragedia-de-2011-na-serra.html. Acessado em: 22 out. 2019.

CARDONA, O. D., VAN AALST, M. K., BIRKMANN, J., FORDHAM, M., MC GREGOR, G., ROSA, P., PULWARTY, R. S., SCHIPPER, E. L. F., SINH, B. T., DÉCAMPS, H., KEIM, M., DAVIS, I., EBI, K. L., LAVELL, A., MECHLER, R., MURRAY, V., PELling, M., POHL, J., SMITH, A. O., THOMALLA, F. Determinants of risk: Exposure and vulnerability. In: Managing the Risks of Extreme Events and Disasters to Advance Climate Change Adaptation: Special Report of the Intergovernmental Panel on Climate Change. Cambridge University Press, 2012, p. 65-108.

CARMO, R. L. D.; ANAZAWA, T. M. Mortalidade por desastres no Brasil: o que mostram os dados. Ciência \& Saúde Coletiva, v. 19, p. 3669-3681, 2014.

DIAS, M. C. D. A.; et al. Estimation of exposed population to landslides and floods risk areas in Brazil, on an intra-urban scale. International Journal of Disaster Risk Reduction, v. 31, p. 449459, 2018.

DOURADO, F. et al. O Megadesastre da Região Serrana do Rio de Janeiro: as causas do evento, os mecanismos dos movimentos de massa e a distribuição espacial dos investimentos de reconstrução no pós-desastre. Anuário do Instituto de Geociências, v. 35, n. 2, p. 43-54, 2012.

FREITAS, Carlos Machado et al. Vulnerabilidade socioambiental, redução de riscos de desastres e construção da resiliência: lições do terremoto no Haiti e das chuvas fortes na Região Serrana, Brasil. Ciência \& Saúde Coletiva, v. 17, 2012. 
FREITAS, Maria Isabel Castreghini; CUNHA, Lúcio. Cartografia da vulnerabilidade socioambiental: convergências e divergências a partir de algumas experiências em Portugal e no Brasil. Urbe: Revista Brasileira de Gestão Urbana, v. 5, n. 1, 2013.

GIDDENS, A. As consequências da modernidade. São Paulo: UNESP, 1991.

HOGAN, D. J. Human dimensions of global environmental change. Ambiente e Sociedade, v. 10, p. 56-72, $2007 \mathrm{~b}$.

HOGAN, D. J..População e meio ambiente: a emergência de um novo campo de estudos. In: Daniel Joseph Hogan. (Org.). Dinâmica populacional e mudança ambiental: cenários para o desenvolvimento brasileiro. Campinas: Nepo/Unfpa, 2007a, p. 1-25.

HOGAN, DanielJoseph.Mobilidadepopulacional, sustentabilidade ambiental e vulnerabilidade social. R. bras. Est. Pop., São Paulo, v. 22, n. 2, p. 323-338, jul./dez. 2005.

HOGAN, Daniel Joseph. População, pobreza e poluição em Cubatão, São Paulo. In: George Martine (Org.). População, meio ambiente e desenvolvimento: verdades e contradições. Campinas: Editora da UNICAMP, 1993.

HOGAN, Daniel Joseph; MARANDOLA JR., Eduardo. Sociodemographic vulnerability to environmental hazards of the metropolis. SOURCE, v. 11, p. 42-48, 2008.

KELMAN, Ilan. Disasters by choice: How our actions turn natural hazards into catastrophes. Oxford University Press, 2020.

MARANDOLA JR, E.; HOGAN, D. J. Natural hazards: o estudo geográfico dos riscos e perigos. Ambiente \& Sociedade, 2004.

MARANDOLA JR, E.; HOGAN, D. J. Vulnerabilidades e riscos: entre geografia e demografia. Revista Brasileira de Estudos de População, v. 22, n. 1, p. 29-53, 2005. 
MARANDOLA JR., Eduardo; HOGAN, Daniel Joseph. Vulnerabilities and risks in population and environment studies. Population and Environment, v. 28, p. 83-112, 2007.

MARCHEZINI, Victor. Processos de recuperação em desastres: discursos e práticas. 1ed. São Carlos: RiMa. 2014.

MARCHEZINI, Victor; FORINI, Henrique Almeida. Dimensões sociais da resiliência a desastres. Redes, v. 24, n. 2, 2019.

MARCHEZINI, Victor; WISNER, B. Challenges for vulnerability reduction in Brazil: Insights from the PAR framework. In: Victor Marchezini; Ben Wisner; Luciana de Resende Londe; Silvia Midori Saito. (Org.). Reduction of vulnerability to disasters: from knowledge to action. 1ed.São Carlos: Rima Editora, 2017, p. 57-96.

MARQUES, César. Os desastres no Rio de Janeiro: conceitos e dados. Cadernos do Desenvolvimento Fluminense, n. 8, p. 55-72, 2015.

MORROW, B.H. Identifying and mapping community vulnerability. Disasters, v. 23, n. 1, p. 1-18, 1999.

PHILLIPS, B. et al. Introduction. In B. D. Phillips, D. S. K. Thomas, A. Fothergill, \& L. Blinn-Pike (Eds.), Social vulnerability to disasters. London: Taylor \& Francis Group. 2010.

PORTELLA, S. L. D.; NUNES, J. A. Populações serranas excluídas, cidades insustentáveis: o enigma da participação pública. Ciência \& Saúde Coletiva, v. 19, p. 4223-4228, 2014.

PORTELLA, S. L. D.; OLIVEIRA, S. S. S. Vulnerabilidades deslocadas e acirradas pelas políticas de habitação: a experiência do Terra Nova. Redução de vulnerabilidade para desastres: do conhecimento a ação, 2017.

ROCHA, G. C. Riscos ambientais: Análise e mapeamento em Minas Gerais. Editora UFJF, 2006.

RODRIGUES, A. C. et al. Delineamento da produção científica sobre desastres no Brasil no início deste século. Desenvolvimento e meio ambiente, v. 34, 2015. 
ROMERO, G.; MASKREY, A. Como entender los desastres naturales. In: MASKREY, A. (Org.). Los desastres no son naturales. Colômbia: La Red., 1992.

SAITO, S. M. Desastres Naturais: conceitos básicos. Inpe. Disponível em: http://www3.inpe.br/crs/crectealc/pdf/silvia_saito. pdf. Acesso em: 04 mai. de 2019. v. 12, 2016.

SCHLEE, M. B. Ocupação de encostas urbanas: algumas considerações sobre resiliência e sustentabilidade. Cadernos Metrópole, v. 15, n. 29, p. 241-264, 2013.

SILVA, Keila Camila; POLETO, Cristiano. Percepções socioambientais de inundações: reflexões sobre o risco. Revista Internacional Interdisciplinar INTERthesis, v. 12, n. 2, 2015.

SOUZA, Marcelo Lopes. Proteção ambiental para quem? A instrumentalização da ecologia contra o direito à moradia. Mercator, v. 14, n. 4, 2015.

TUFEKCI, S.; WALLACE, W. A. The emerging area of emergency management and engineering. IEEE Transactions on Engineering Management, v. 45, n. 2, 1998.

VALENCIO, Norma et al. A produção social do desastre: dimensões territoriais e político-institucionais da vulnerabilidade das cidades brasileiras frente às chuvas. Teoria \& Pesquisa, v. 1, n. 44, 2004.

VALENCIO, Norma et al. Implicações éticas e sociopolíticas das práticas de Defesa Civil diante das chuvas: reflexões sobre grupos vulneráveis e cidadania participativa. São Paulo em perspectiva, v. 20, n. 1, 2006.

VALENCIO, Norma. Desastres, ordem social e planejamento em defesa civil: o contexto brasileiro. Saúde e Sociedade, v. 19, p. 748762, 2010.

VALENCIO, Norma. Desastres: tecnicismo e sofrimento social. Ciência \& Saúde Coletiva, v. 19, n. 9, 2014. ROMERO, G.; MASKREY, A. Como entender los desastres naturales. In: MASKREY, A. (Org.). Los desastres no son naturales. Colômbia: La Red., 1992. 